\section{International Scientific Journal Theoretical \& Applied Science}

\author{
p-ISSN: 2308-4944 (print) e-ISSN: 2409-0085 (online) \\ Year: 2015 Issue: 05 Volume: 25
}

Published: $30.05 .2015 \quad$ http://T-Science.org

SECTION 12. Geology. Anthropology. Archaeology.
Inna Aleksandrovna Serebryanik

Candidate of technical sciences,

Associate Professor of the

Department of World economy,

Irkutsk National Research Technical University,

Russia

nasamolet@yandex.ru

\section{Alena Viktorovna Druzhinina}

student,

Irkutsk National Research Technical University,

Russia

alena.druzhinina@mail.ru

\title{
MICA: MAIN CHARACTERISTICS OF GRINDING
}

Abstract: The article discusses the features of mica, as crushed material. Presents the problems the selection of grind type. Analyzed the shape factor of particles in various types of grinding.

Key words: mica, milling, particle, surface shape, crystal.

Language: Russian

Citation: Serebryanik IA, Druzhinina AV (2015) MICA: MAIN CHARACTERISTICS OF GRINDING. ISJ Theoretical \& Applied Science 05 (25): 9-13.

Soi: http://s-o-i.org/1.1/TAS*05(25)3 Doi: crossef http://dx.doi.org/10.15863/TAS.2015.05.25.3

\section{СЛЮДА: ОСНОВНЫЕ ХАРАКТЕРИСТИКИ ПОМОЛА}

Аннотация: В статье рассмотрены особенности слюды, как измельчаемого материала. Представлень проблемы выбора типа помола. Проанализирован коэффициент формы частиц при различных типах помола.

Ключевые слова: слюда, помол, частица, коэффицичен формы, кристалл.

Прочность - это способность твердого тела оказывать сопротивление разрушению под внешним воздействием [9, с.80], когда рвутся связи меду частицами кристаллической структуры без изменения агрегатного состояния вещества.

Теоретической прочностью называют прочность твердого тела, имеющего идеальную кристаллическую структуру. Теоретическую прочность можно рассчитать по силам взаимодействия частиц в кристалле. Реальная прочность тела на несколько порядков меньше теоретической. Это объясняется тем, что в теле имеются дефекты кристаллической структуры, микропоры и микротрещины.

Дефекты кристаллической структуры подразделяются на точеные и линейные. Точечные - это вакансии, т.е. незанятые узлы кристаллической решетки или внедрения чужеродных атомов. Линейные - это дислокация или смещение одной части кристалла относительно другой.

Слюды - это группа минералов, характеризующаяся необыкновенно совершенной спаянностью, которые чрезвычайно легко делятся на тонкие листочки. В химическом отношении слюды - это алюмосиликаты, главным образом, калия, магния, лития, натрия, реже извести, железа. Кроме того, в них содержится небольшое количество воды, а в некоторых наблюдается фтор. Несмотря на многочисленные анализы, до сих пор не установлены точные химические формулы слюд.

Кристаллическая структура слюд громоздка и сложна. При одном и том же химическом составе существует целый ряд структурных форм, образующих многочисленные политипы. Крупные кристаллы слюд нередки, но их грани образованы несовершенно, что мешает точному определению углов между ними. По этой причине кристаллическая система слюд сначала была определена неправильно. Общий вид кристаллов приближается к ромбической или гексагональной системе, к которым слюды и были относимы. Точные оптические исследования показали, что все слюды принадлежат одноклимерной системе. У всех слюд плоскость оптических осей почти перпендикулярна к плоскости спаянности, идущей параллельно третьему (основному) пинакоиду. К этой же плоскости почти перпендикулярно идет острая биссектриса, от этого пластинки слюды в сходящемся поляризованном свете обнаруживают выходы 
оптических осей. Угол их расхождения весьма различен (от 0 до $75^{\circ}$ ). Относительно других граней оптических осей у слюд - располагается двояко: в одних она перпендикулярна второму пинакоиду (это так называемые слюды 1-го рода), у других она параллельна той же плоскости (слюды 2-го рода). Вследствие этого при ударе острием пластинки слюды на ней получаются трещины (в виде шестилучевой звезды).

Для семейства слюд характерны различного рода замещения и включения. По этой причине установленные экспериментальными методами параметры элементарной ячейки, ее симметрия, конфигурация атомов, структура не совпадают для различных образцов. В настоящее время в литературе [7] при описании структуры слюд (рис.1) вводится ряд допущений, способствующих получению наиболее простой для понимания и изучения элементарной ячейки. Наиболее важные из них, это:

1) представление структуры в виде ряда слоев, в основе которых лежит идеальная гексагональная сетка;

2) устранение различий между алюмо- и кремнекислородными тетраэдрами;

3) объединение плоскостей гидроксилионов и атомов кислорода из вершин тетраэдров;

4) использование простых наложений и сдвигов слоев, отвечающих соображениям симметрии.

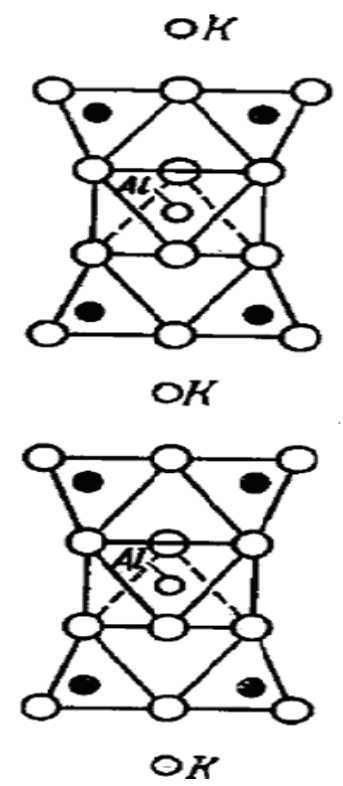

Рисунок 1 - Схематическое изображение структуры слюды.

\begin{abstract}
В минералах группы слюд тетраэдрические слои обычно сложены кремне- и алюмокислородными тетраэдрами, а между трехслойными пакетами располагаются ионы К, компенсирующие избыточные заряды пакетов. В гидрослюдах наряду с ионами К между пакетами присутствуют ионы оксония $\left(\mathrm{H}_{3} \mathrm{O}\right)^{+}$, молекулы воды и гидратированные ионы магния $\mathrm{Mg}(\mathrm{OH})^{+}$.
\end{abstract}

Дефекты пластинок слюды значительно отражаются на ее физических, механических и электроизоляционных свойствах. Причем в силу того, что кристаллы слюды имеют свойство передавать без значительных изменений характер микронеровностей поверхностей (микрорельеф) через всю толщину кристалла, то даже самые маленькие пластины слюды сохраняют все основные свойства, характеризующие качество крупнолистовой слюды.

Различные твердые материалы в зависимости от их физических свойств при измельчении в одинаковых условиях с затратой одинакового количества энергии дают продукты, характеризующиеся различной степенью дисперсности. Следовательно, разные материалы обладают разной способностью к измельчению.

Соответственно, для каждого вида материала существует наиболее рациональный способ его разрушения (измельчения), учитывающий индивидуальные физические свойства данного материала.

При измельчении слюды в зависимости от применяемого аппарата измельчения получают смесь, состоящую из пластинок, обладающих различной степенью повреждаемости или дефектности внешней поверхности, т.е. различный по качеству продукт.

Разнообразие форм частиц разных способ помола объясняется тем, что в процессе измельчения в кристаллах слюды могут появляться или фигуры удара или фигуры давления. 
Округлая форма частиц, получающая при шаровом помоле, соответствует фигуре давления. При струйном и молотковом измельчении форма соответствует фигурам удара. Слюдяные пластинки, измельченные на шаровой мельнице, имеют округлую форму, на молотковой дробилке - форму вытянутого эллипса. При струйном помоле форма частиц слюды представляет неправильный многоугольник.

В большинстве случаев частицы порошкообразных материалов имеют сложную неправильную форму, для её точного описания требуется большое число параметров, главным из которых, как правило, является размер частицы $[8$, c.9]. Однако это понятие не вполне определено: если для шарообразной или кубической частицы единственный показатель ее крупности - диаметр или длина ребра, то для частицы неправильной формы существует бесконечное число способов определения трех ее измерений. При выборе способа определения крупности частиц следует отдавать предпочтение тому процессу, который наиболее близок по своей природе к реальному технологическому, в котором используется конечный продукт.

Качество слюды принято характеризовать величиной полезной площади пластины, т.е. той площадью, которая не содержит трещин, вздутостей, пятен, посторонних включений и т.д. Даже самые малые по величине пластинки обладают хорошо выраженной полезной площадью. В связи с этим представляет интерес определение величины полезной площади слюды в зависимости от способа помола (1)

$$
f=S r^{u з м .} / S r^{\text {mеор. }}
$$

где $f$ - коэффициент формы;

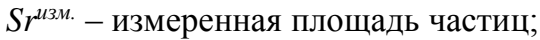

$\mathrm{Sr}^{\text {mеор. }}$ - теоретическое значение площади.

Значение коэффициента формы для различных классов крупности пластин молоткового, шарового и струйного помола приведено в таблице 1.

Таблица 1

Значение коэффициента, учитывающего форму частиц слюды при измельчении в различных измельчителях.

\begin{tabular}{|c|c|c|c|c|c|}
\hline Помол & $\begin{array}{c}\text { Класс } \\
\text { крупности, м }\end{array}$ & $\begin{array}{l}\text { Значение } \\
\mathrm{Sr}^{\text {изм }}, \mathrm{MM}^{2} \\
\end{array}$ & $\begin{array}{c}\text { Значение } \\
\mathrm{Sr}^{\text {теор }}, \mathrm{Mм}^{2} \\
\end{array}$ & $\mathrm{f}=\mathrm{Sr}^{\text {изм }} / \mathrm{Sr}^{\mathrm{Teop}}$ & $f_{\mathrm{cp}}$ \\
\hline \multicolumn{6}{|c|}{ Мусковит } \\
\hline \multirow{10}{*}{ Молотковый } & $-2+1$ & 3,21 & 3,14 & 1,02 & \multirow{5}{*}{1,362} \\
\hline & $-1+0,63$ & 1,4 & 0,785 & 1,78 & \\
\hline & $-0,63+0,4$ & 0,57 & 0,31 & 1,84 & \\
\hline & $-0,4+0,2$ & 0,14 & 0,13 & 1,08 & \\
\hline & $-0,2+0,1$ & 0,034 & 0,031 & 1,09 & \\
\hline & & & гопит & & \\
\hline & $-2,5+1,6$ & 6,93 & 4,9 & 1,41 & \multirow{4}{*}{0,885} \\
\hline & $-1,6+0,63$ & 1,41 & 2,0096 & 0,7 & \\
\hline & $-0,63+0,4$ & 0,16 & 0,31 & 0,51 & \\
\hline & $-0,4+0,2$ & 0,12 & 0,13 & 0,92 & \\
\hline \multicolumn{6}{|c|}{ Мусковит } \\
\hline \multirow[t]{5}{*}{ Шаровый } & $-2,5+1,6$ & 6,82 & 4,9 & 1,39 & \multirow{5}{*}{1,422} \\
\hline & $-1,6+0,63$ & 1.67 & 2,0096 & 0,83 & \\
\hline & $-0,63+0,315$ & 0,34 & 0,311 & 1,09 & \\
\hline & $-0,315+0,2$ & 0,1096 & 0,0779 & 1,4 & \\
\hline & $-0,2+0,1$ & 0,075 & 0,031 & 2,4 & \\
\hline \multicolumn{6}{|c|}{ Мусковит } \\
\hline \multirow{8}{*}{ Струйный } & $-1+0,63$ & 2,37 & 0,785 & 1,74 & \multirow{3}{*}{2,24} \\
\hline & $-0,63+0,315$ & 0,46 & 0,31 & 1,48 & \\
\hline & $-0,315+0,2$ & 0,237 & 0,0779 & 3,04 & \\
\hline & \multicolumn{5}{|c|}{ Флогопит } \\
\hline & $-1+0,63$ & 1,16 & 0,785 & 1,48 & \multirow{4}{*}{1,51} \\
\hline & $-0,63+0,4$ & 0,47 & 0,31 & 1,52 & \\
\hline & $-0,4+0,315$ & 0,2 & 0,13 & 1,54 & \\
\hline & $-0,315+0,2$ & 0,1174 & 0,0779 & 1,5 & \\
\hline
\end{tabular}

Наибольшую величину, равную 2,24, коэффициент $f$ принимает для пластин мусковита струйного измельчения.
Согласно результатам исследований (Байбородин Б.А., Плахова Е.К. и др.), было доказано, что при:
ISPC Industry \& Technology Europe,

Lyon, France 
Impact Factor ISRA (India) $\quad=\mathbf{1 . 3 4 4}$

Impact Factor ISI (Dubai, UAE) $=\mathbf{0 . 8 2 9}$

based on International Citation Report (ICR)

Impact Factor GIF (Australia) $\quad \mathbf{0} \mathbf{0 . 3 5 6}$ $\begin{array}{lr}\text { Impact Factor JIF } & =\mathbf{1 . 5 0 0} \\ \text { Impact Factor SIS (USA) } & =\mathbf{0 . 9 1 2} \\ \text { Impact Factor PИНЦ (Russia) } & =\mathbf{0 . 1 7 9} \\ \text { Impact Factor ESJI (KZ) } & =\mathbf{1 . 0 4 2}\end{array}$

1) шаровом измельчении частицы слюды круглой формы, сильно деформированы, много трещин. Края неровные, сильно расслоенные, небольшие размеры полезной площади;

2) молотковом дроблении пластинки вытянутой формы, повреждаемость небольшая. Наблюдается наличие полезной площади на слюдяных частицах, деформация по большой оси, края ровные;

3) при струйном измельчении частички слюды угловатой формы, напоминающей неправильные многоугольники, повреждаемость частиц малая, наблюдается наличие большой полезной площади. Деформация на выступах, трещин почти нет, небольшие расслоения по краям; поверхность ровная, гладкая.

Следовательно, для сравнительно большого числа конечных продуктов, было бы целесообразнее применять слюду струйного помола, в силу большей полезной площади, нежели при других видах помола и меньшей деформации. Слюда струйного помола применима в производстве некоторых композиционных материалов, в том числе и микалекса.

Микалекс - твердый плотный негигроскопичный композиционный материал, получаемый путем прессования и термической обработки смеси молотой слюды мусковит и легкоплавкого стекла. Микалекс характеризуется высокими диэлектрическими свойствами, механической прочностью, термостойкостью и хорошей механической обрабатываемостью, используется в качестве вставок в дугогасителных камерах электровозов и переходных клемников в напольных электрических печах; электровакуумной технике (держатели мощных ламп, гребенки катушек индуктивности, платы и т.д.), радиотехнической и электротехнической промышленности для изготовления плат и различных деталей.

Исходным сырьем для производства микалекса служит молотая слюда и специальное стекло. Технологическая схема производства микалекса состоит из следующих этапов (рис. 2).

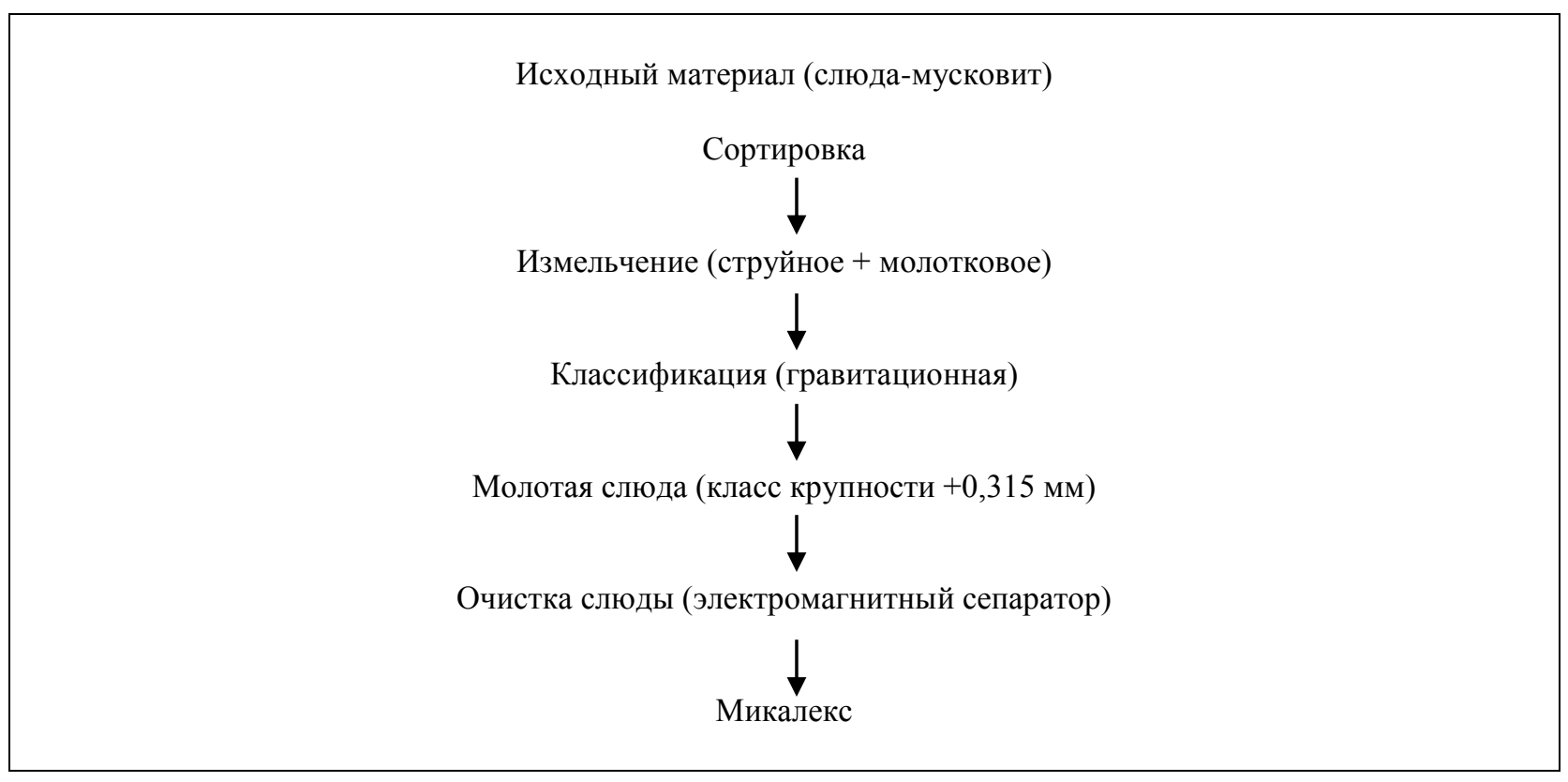

Рисунок 2 - Технологическая схема производства микалекса.

Таким образом, процессы помола и классификации занимают значимое место в подготовке слюды, используемой при производстве микалекса.

\section{References:}


1. Akunov VI (1985) Strujnoe izmel'chenie gornyh porod. Gornyj zhurnal. 1985. №4. pp.35-38.

2. Bilenko LF (1984) Zakonomernosti izmel'chenija v barabannyh mel'nicah. Moscow: Nedra, 1984. -200 p.

3. Gardner RP, Austin LG (1966) Trudy evropejskogo soveshhanija po izmel'cheniju. Moscow: Strojizdat, 1966. -248 p.

4. Gorobec VI, Gorobec LZ (1977) Novoe napravlenie rabot po izmel'cheniju. Moscow: Nedra, 1977. 180 p.

5. Kirij VG, Serebrjanik IA (2005) Modelirovanie processa istiranija $\mathrm{v}$ psevdoozhizhennom sloe strujnoj mel'nicy. Tehniko-jekonomicheskie problemy razvitija regionov: materialy nauchno-prakticheskoj konferencii (december, 2005). Irkutsk : Izd-vo IrGTU, 2005. pp.76-81.

6. Lashev EK (1948) Sljuda. Moscow: Strojizdat, 1948. $289 \mathrm{p}$.

7. Linch A (1981) Cikl droblenija i izmel'chenija: modelirovanie, optimizacija, proektirovanie. Moscow: Nedra, 1981. 456 p.

1. 8. Mizonov VE, etc. (1998) Ob opredelenii matricy izmel'chenija v matematicheskoj mode, razmole tverdogo topliva // Trudy ITJeU. Ivanovo, 1998. -84 p.

8. Perov VA, etc. (1990) Droblenie, izmel'chenie i grohochenie poleznyh iskopaemyh. Moscow: Nedra. 1990. -415 p.

9. Fridman SJ (1985) Obogashhenie poleznyh iskopaemyh. Moscow: Nedra, 1985. 